\title{
The strange ways of the tammar wallaby
}

\author{
SCIENTIFIC NAME \\ Macropus eugenii \\ TAXONOMY \\ PHYLUM: Chordata \\ CLASS: Mammalia \\ INFRACLASS: Marsupialia \\ ORDER: Diprodontia \\ FAMILY: Macropodidae
}

\section{Physical description}

The tammar wallaby is a small marsupial mammal weighing up to $9 \mathrm{~kg}$ and standing 59-68 cm tall. Tammars have narrow, elongated heads with large pointed ears. Their tapered tails measure $33-45 \mathrm{~cm}$ in length. The tammar's coat is dark gray to brown dorsally, reddish on the sides of the body and limbs and pale gray or tan ventrally.

Tammars have strong hind legs and feet that are specialized for hopping, their primary means of locomotion. They can hop at a frequency of 3.5 strides per second and cover $0.8-2.4 \mathrm{~m}$ in a single hop ${ }^{1}$. For many mammals, the rate of oxygen use increases linearly with the rate of speed, but this does not hold for wallabies, whose oxygen use levels off as their speed increases ${ }^{2}$. As they hop, tammars store elastic strain energy in the tendons of their hindlimbs when their feet contact the ground, which is then recovered through recoil action when they leave the ground ${ }^{3}$. The amount of energy stored increases with the tammar's speed and weight $^{2}$, allowing a mother to carry a joey while hopping without expending extra energy $y^{4}$

\section{Reproduction}

Wallabies gather in large groups called mobs and have a seasonal, promiscuous mating pattern. Like most marsupials, the female tammar has a pouch in which she nurses her offspring.

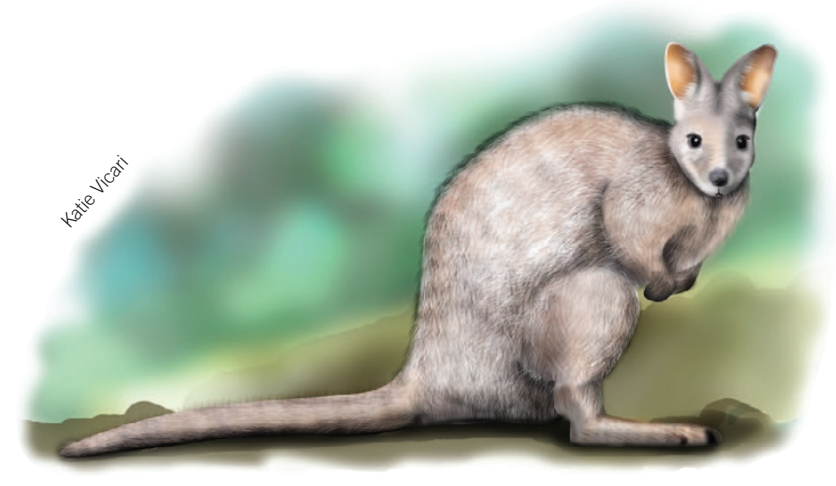

If she becomes pregnant while carrying a joey in her pouch, development of the embryo is arrested until the joey leaves, a phenomenon called embryonic diapause ${ }^{5}$. Tammars have been used in studies of mammalian reproduction, androgen transport and sperm production ${ }^{5,6}$.

\section{Research résumé}

Marsupials are of great interest in comparative genomics. The tammar wallaby is the second marsupial (following the shorttailed opossum Monodelphis domestica) and first macropod to have its genome sequenced ${ }^{7}$. Sequence analysis identified new types of small RNAs, reorganization of immune genes, innovation in reproduction and lactation genes, and expansion of olfaction genes in tammars compared with other mammals ${ }^{7}$.

Lactation is far more sophisticated in wallabies than in placental mammals and is the subject of frequent study. A recent report identified 14 genes expressed in the mammary gland during early lactation encoding peptides called cathelicidins that kill a broad range of bacterial pathogens. One cathelicidin was effective against multidrug-resistant strains of the bacteria Pseudomonas aeruginosa, Klebsiella pneumoniae and Acinetobacter baumannii ${ }^{8}$.

But pathogens aren't the only bacteria of interest in wallaby research. A new bacterium in the Succinivibrionaceae family of the Proteobacteria phylum has been identified in the foregut of the tammar. Because this species produces very little methane during rumination, scientists suggest that further investigation could lead to the development of new strategies to redirect fermentation in domestic livestock in order to reduce their methane emissions ${ }^{9}$.

1. Baudinette, R.V., Gannon, B.J., Runciman, W.B., Wells, S. \& Love, J.B. Do cardiorespiratory frequencies show entrainment with hopping in the tammar wallaby? J. Exp. Biol. 129, 251-263 (1987).

2. Baudinette, R.V., Snyder, G.K. \& Frappell, P.B. Energetic cost of locomotion in the tammar wallaby. Am. J. Physiol. 262, R771-R778 (1992).

3. Biewener, A.A. \& Baudinette, R.V. In vivo muscle force and elastic energy storage during steady-speed hopping of tammar wallabies (Macropus eugenii). J. Exp. Biol. 198, 1829-1841 (1995).

4. Baudinette, R.V. \& Biewener, A.A. Young wallabies get a free ride. Nature 296, 653-654 (1998).

5. Hickford, D., Frankenberg, S. \& Renfree, M.B. The tammar wallaby, Macropus eugenii: a model kangaroo for the study of developmental and reproductive biology. in Emerging Model Organisms: A Laboratory Manual Vol. 2 (Cold Spring Harbor Laboratory Press, Woodbury, NY, 2009).

6. Jones, R.C. Reproduction in male Macropodidae. in Kangaroos, Wallabies and Rat-kangaroos (eds. Grigg, G., Jarman, P. \& Hume, I.) 287-305 (Surrey Beatty \& Sons, New South Wales, Australia, 1989).

7. Renfree, M.B. et al. Genome sequence of an Australian kangaroo, Macropus eugenii, provides insight into the evolution of mammalian reproduction and development. Genome Biol. 12, R81(2011).

8. Wang, J. et al. Ancient antimicrobial peptides kill antibiotic-resistant pathogens: Australian mammals provide new options. PLOS ONE 6, e24030 (2011).

9. Pope, P.B. et al. Isolation of Succinivibrionaceae implicated in low methane emissions from tammar wallabies. Science 333, 646-648 (2011). 